\title{
A UTOPIA DO CONTRATO SOCIAL: A QUESTÃO DAS HIDRELÉTRICAS NA AMAZÔNIA
}

Débora Prissila Reis Sandim - deborasandim@gmail.com

Universidade Federal Rural da Amazônia

Sarah Dias Azevedo - saaahazevedo@gmail.com

Universidade Federal Rural da Amazônia

Leandro Marques Torres - Leandrotorres15@yahoo.com.br

Universidade Federal Rural da Amazônia

Paulo Rick Soares Rodrigues - rickpaulo83@gmail.com

Universidade Federal Rural da Amazônia

Wanderley Augusto da Silva Pinto - wanderleysilva1503@gmail.com

Universidade Federal Rural da Amazônia 


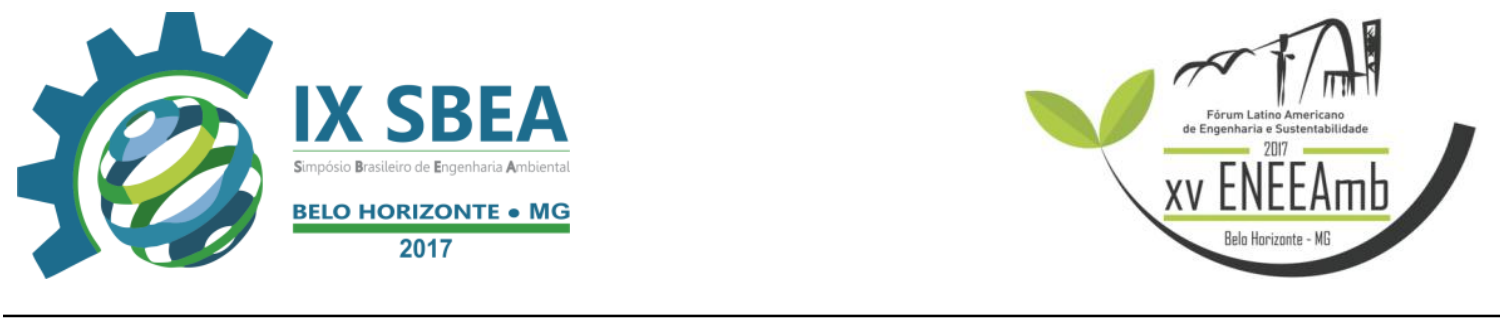

\section{Resumo}

O objetivo principal do trabalho consiste na apresentação de fatos à cerca das problemáticas advindas de usinas hidrelétricas; com ênfase em Belo Monte, localizada no município de Altamira/PA. Serão discorridos os verdadeiros impactos sociais e ambientais que, por diversas vezes, foram mascarados pela mídia e governo. Desbravaremos o histórico desta construção, assim como as manifestações sociais que percorreram e percorrem a UHE Belo Monte, e até que ponto foi efetuado o seu planejamento. Conhecendo a relação entre o contrato social de Rousseau e sua idealização utópica na modernidade.

\section{Introdução/Objetivo}

A Constituição Federal é um contrato social leonino, onde se assenta a melhores condições de vida, mas sem o devido cumprimento (MARTINS, 2013). Uma vez que na atualidade as desigualdades sociais são dissimuladas.

A constituição Federal 1988 (CF/88), no seu artigo Art. 225. Diz: "Todos têm direito ao meio ambiente ecologicamente equilibrado, bem de uso comum do povo e essencial à sadia qualidade de vida, impondo-se ao poder público e à coletividade o dever de defendê-lo e preservá-lo para as presentes e futuras gerações”.

Apesar da CF/88 estabelecer como um dos direitos fundamentais o direito ao meio ambiente ecologicamente equilibrado em tese, na realidade não garante efetiva preservação ambiental. Uma vez que os grandes empreendimentos no âmbito ambiental, os interesses individuais de grandes empresas se sobressaem ao coletivo. Caso, constatado no processo de implantação da Hidrelétrica de Belo Monte, no qual ocorreram grandes manifestações e petições contra a mesma, mas a "sede enérgica Brasileira" sobressaiu-se aos impactos sociais, ambientais e culturais que poderiam ser ocasionados.

Dessa forma, na implantação de Hidrelétricas na região Amazônica, mascaram-se os verdadeiros impactos, em detrimento da tese ilusória de que o país necessita de energia elétrica para suprir uma eminente crise energética. Retomando o que diz a CF/88 $\S 4$. $^{\text {o: }}$ “A Floresta Amazônica brasileira (...) são patrimônio nacional, e sua utilização far-se-á, na forma da lei, dentro de condições que assegurem a preservação do meio ambiente, inclusive quanto ao uso dos recursos naturais". No tocante, sendo um direito fundamental, as manifestações contra a implantação de Hidrelétricas na Amazônia deveriam ser 


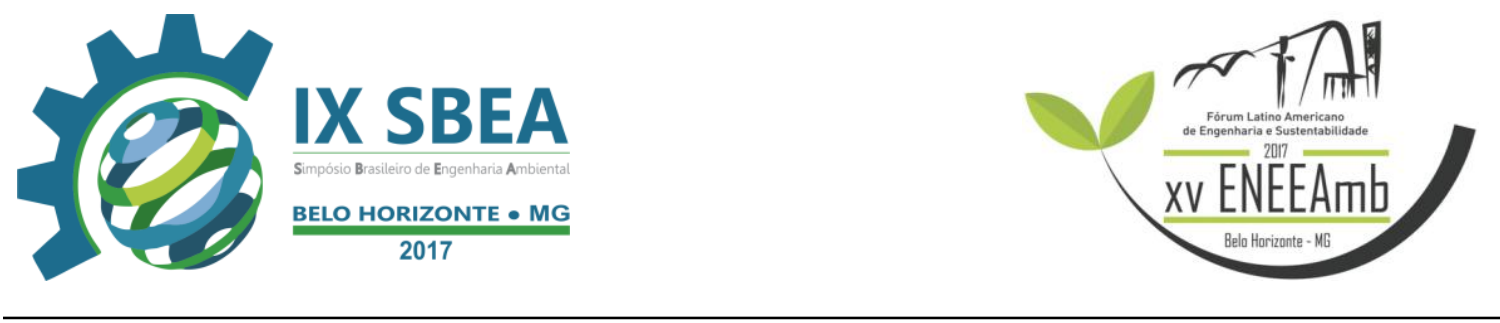

atendidas, pois além de não assegurar a preservação ambiental destrói o patrimônio da humanidade. Como se esse bem de uso de todos fosse propriedade privada do capitalismo que tenta convencer o país que para desenvolver-se precisa aumentar sua geração de energia, o que teoricamente é um objetivo para atender o coletivo.

Porém, de acordo com a teoria de Jean - Jacques Rousseau, quando determinado grupos detém algo para si, como a posse de propriedades, o contrato social é quebrado. Dessa forma, o povo seria passivo neste contrato, isto é, não seria o agente do processo de elaboração das leis e de cumprimento destas, e não sendo ato de liberdade, o qual não beneficiaria a coletividade e sim grupamentos dominantes da sociedade civil, com a criação de novas hidrelétricas. Nesse sentido, o que as grandes companhias enérgicas pregam a sociedade é a utopia de que os preceitos do contrato social serão estabelecidos, quando convence que a necessidade energética configura todo o Brasil.

\section{Metodologia}

Afim de alcançar o objetivo dessa pesquisa foi realizado o levantamento bibliográfico a respeito da problemática das usinas no brasil, buscando-se fontes especializadas na temática, assim com um levantamento do histórico dessas construções dando destaque aos conflitos e incoerências que cercam tais projetos.

Tal qual, ocorreu a análise do contrato social de Rousseau e a influência de suas ideias na organização das sociedades modernas, uma vez que a Constituição Federal é um contrato social leonino, a sua análise também foi indispensável nesse trabalho, pois assim foi possível observar como a teoria é aplicada na pratica em uma sociedade.

\section{Resultados e Discussão}

O contrato social é uma série de questionamentos e pensamentos ditando o modelo para uma sociedade ideal. É a padronização das estruturas sociais com o intuito de ter-se uma organização social justa e moderada. Neste modelo, descrito por Rousseau, um dos pressupostos fundamentais se baseia em: "Há muitas diferenças entre a vontade de todos e a vontade geral: esta olha somente o interesse comum, a outra o interesse privado, e outra coisa não é senão a soma de vontades particulares; mas tirai dessas mesmas vontades as que em menor ou maior grau reciprocamente se destroem, e resta como soma das diferenças a vontade geral" (ROUSSEAU, 2006 p. 41). 


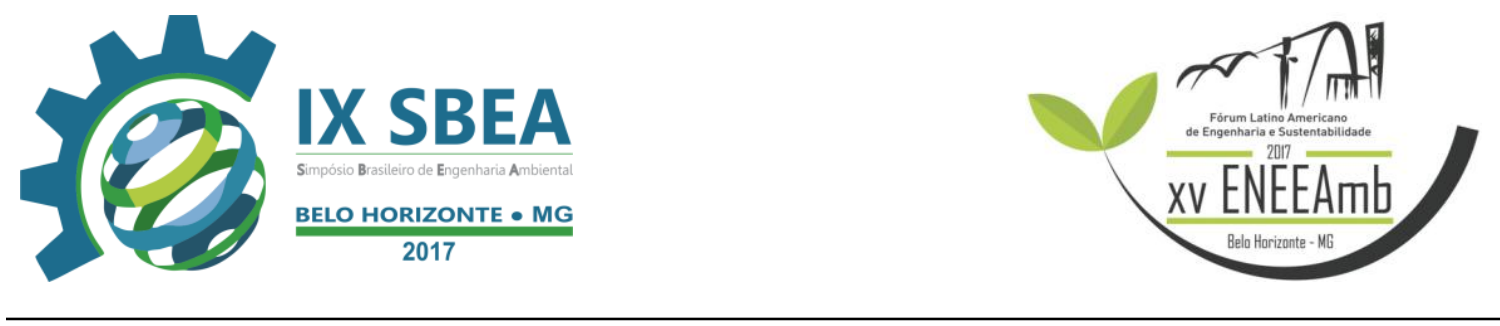

Dessa forma, o que norteia uma sociedade justa e equilibrada é o bem comum a todos, sem privilegiar vontades de uma minoria. E ainda: "Portanto, a fim de se ter o perfeito enunciado da vontade geral, importa não haja no estado sociedade parcial e que cada cidadão só manifeste o próprio pensamento (...). Pois se houver sociedades parciais, será necessário multiplicar o seu número e prevenir a desigualdades entre elas, (...). Tais preocupações são as únicas adequadas para que a vontade geral esteja sempre esclarecida e o povo de modo nenhum se equivoque" " (ROUSSEAU,2006 p. 42).

No tocante não somente o soberano tem funções nessa organização social, mas o cidadão. Destaca-se, porém que, se não houver uma previa analise da necessidade do povo por parte do soberano, não efetivamente ter-se-á politicas e leis justas. Conforme descreve Jean - Jacques Rousseau: "Assim como um grande arquiteto, antes de construir, observa e sonda o solo, para ver se este tem condições de sustentar o peso, o sábio instituidor não começa por redigir boas leis em si mesmas; mas examina anteriormente se o povo, ao qual são destinadas, está apto para as aceitar." "(ROUSSEAU,2006 p.61-62).

Dentro dessa perspectiva, o contrato social tornou-se atualidade uma busca intensa pela igualdade entre as classes e seus governantes. Uma utopia, com anseio a minimização dos impactos sociais negativos corriqueiros no século XXI. Desses impactos sociais, avulta a crise energética de 2001, chamado de “Apagão". O cenário se deu no governo do presidente Fernando Henrique Cardoso (FHC), que correspondeu a seus dois mandatos (1995-1998 e 1999-2002). Na sua governança FHC iniciou uma reforma no estado, tendo como base a privatização de alguns setores principais, que segundo ele objetivava, "a reestruturação econômica do Estado, através da diminuição da dívida pública e melhoria do seu perfil” (SROUR, 2005).

Entre junho de 2001 e fevereiro de 2002, o Sudeste, o Centro-Oeste e o Nordeste do Brasil passaram por um corte de consumo de energia de $20 \%$ e, por precaução, a região Norte também ficou sob racionamento, de agosto a dezembro de 2001. Na versão oficial, essa situação fora causada pelo fato da transição para o novo modelo setorial não ter sido concluída e pela estiagem, a qual provocara um esvaziamento dos reservatórios das hidrelétricas, uma vez que a maior parte da geração de energia elétrica no Brasil é de origem hidráulica (SROUR, 2005). 


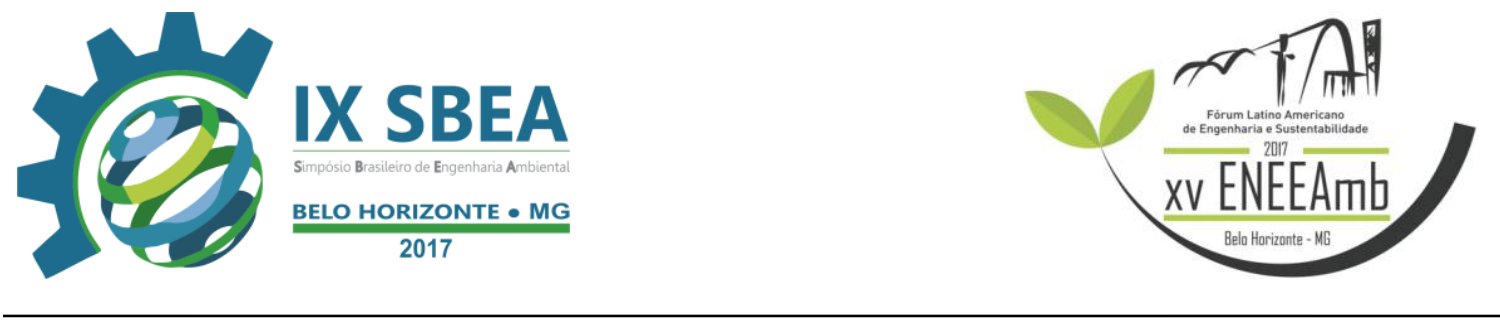

Com isso, a abordagem sobre a ideia da necessidade emergencial de construir e expandir mais hidrelétricas começou a se vendida à população brasileira, como uma solução para a crise energética: "Entende-se que as medidas de conservação de energia e repotenciação de usinas hidrelétricas existentes são ações importantes para atender a demanda crescente de energia elétrica do país. Todavia, são insuficientes para suprir a demanda prevista para os próximos anos (Projeto da Usina de Belo Monte- Perguntas Frequentes, 2011)".

Assim a apresentação do projeto de belo monte a sociedade se baseou, em parte, nessa afirmação anterior. Uma vez que era necessário justificar a grandiosidade dessa obra de engenharia em detrimento dos impactos sociais e ambientais que a mesma traria no seu local de instalação, a chamada "mentira institucionalizada", que seria defesa de que belo monte é mais uma barragem no Xingu, ou seja, é inviável economicamente porque o fluxo de água altamente sazonal no rio deixaria a principal casa de força de 11.000 MW, essencialmente inativa por 3-4 meses do ano (NADER, 2008).

Nesse contexto, tendo em vista o histórico para aprovação da construção da UHE Belo Monte e as inúmeras manifestações sociais e contrariedades da real necessidade de investir nessa construção, questiona-se: "Porque construir mais hidrelétricas, se não é uma energia limpa e nem rentável economicamente? "Precisamos realmente de toda essa energia?" "A construção da UHE Belo Monte é um exemplo vivo de quebra de contato social, de acordo com os postulados de Rousseau?".

Estudo da WWF Brasil chamado "Agenda elétrica sustentável Brasil”, mostra uma série de dados e analises do setor energético brasileiro e uma projeção sustentável até 2020. Nesse estudo diz que a repotenciação de usinas mais antigas seria mais eficiente em detrimento a construir novas hidrelétricas, $15 \mathrm{GW}$ poderiam ser acrescentados a capacidade instalada até 2020. "Estima-se que é possível obter ganhos em instalações que hoje correspondem a $32 \mathrm{GW}$ instalados (todas acima de 20 anos de uso), com custos de R\$ 250-600/ kW adicionado" (CGEE, 2003).

Outro ponto seria o melhoramento no sistema de transmissão e distribuição em vista a reduzir as perdas, que são consideráveis. "Estima-se que 16-17\% da eletricidade gerada seja perdida ao longo da cadeia de transmissão e distribuição no Brasil” (WWF, 2005). Além do investimento em fontes renováveis se somaria a essa melhoria energética. 


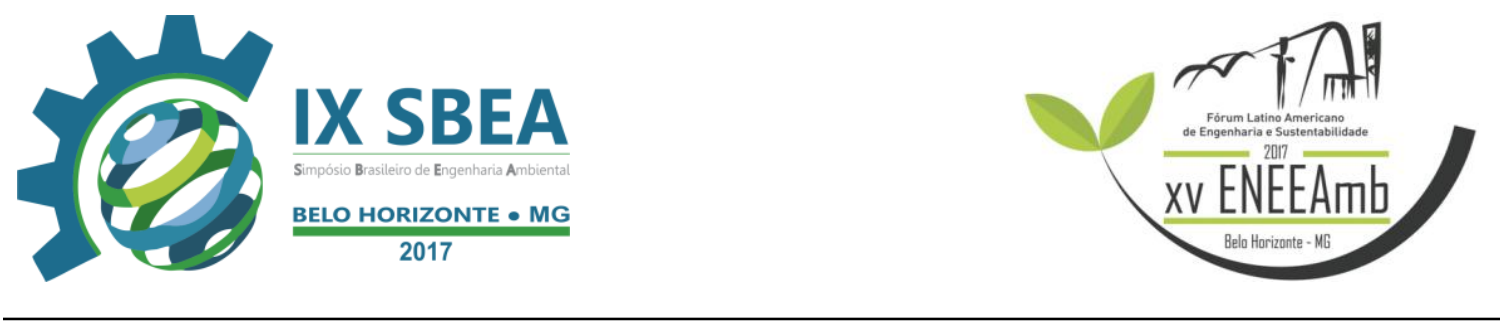

Assim as motivações de mais hidrelétricas são individuais ou políticos ou de grandes empresas alocadas nesses municípios. Que no caso de Altamira-Pará, são indústrias de extração de alumino que necessitam de uma grande porcentagem de energia para seu funcionamento. Além da movimentação de milhões no setor da construção civil.

Foi movido contra Belo Monte, 57 ações contrário a sua construção, por entidades como Defensoria Pública do estado do Pará e organizações não governamentais (MPF/PA, 2013). Além das inúmeras manifestações por comunidades indígenas Altamira e ONGs de cunho ambiental. Dessa forma ficando claro que a sociedade era contra a criação dessa usina. Pois os benefícios não foram convincentes e os estudos realizados para desmentir as afirmações que justificariam essa grandiosa obra foram comprovados.

A UHE Belo Monte mostra que o contrato social na modernidade é uma utopia, uma constante luta entre a sociedade brasileira e seus soberanos. A venda de uma falácia a sociedade e que por mais que as lutas sejam e continuam sendo intensas estão sendo perdidas. Pois a vontade individual, de quem detém o controle econômico tem vencido a vontade coletiva, apaziguando os impactos sociais e ambientais com "mentiras institucionalizadas".

Destaca-se, por fim, a intensidade do ilusório contrato social das hidrelétricas, que os Direitos Fundamentais coletivos e individuais da $\mathrm{CF} / 88$ foram afirmativamente ignorados.

\section{Conclusões/Recomendações}

A Usina de Belo Monte é uma grande obra de engenharia, com vista ao atendimento a suprir a necessidade energética Brasileira. A mesma se juntaria as demais hidrelétricas existentes, objetivando estar no ranking das maiores hidrelétricas mundiais. Porém a ideologia de carência energética é em parte real, e não tão alarmante como é idealizado pelo governo. Apesar da idealização das obras de Belo Monte permearem pelo ano de 1975, o apagão de 2001 serviu como combustível para justificar a potenciação da construção da UHE. As comunidades atingidas diretas e indiretamente foram desde o início contra essa obra, havendo inúmeras manifestações sociais e ainda vários estudos que comprovaram que os benefícios de Belo Monte foram superestimados em detrimento dos impactos sociais e ambientais. Pois, a repotenciação das usinas existentes e investimento em energias renováveis seriam o suficiente para suprir a demanda 
energética. Nesse sentido, Belo Monte é o exemplo atual de que o contrato social postulado por Rousseau é atrevidamente quebrado e dessa forma não existe igualdade de direitos, sendo assim uma sociedade não ideal. Uma utopia pregada com "mentiras institucionalizadas" para o benefício de minorias, como descrito por Rousseau, caracterizando-se como sociedades parciais (o governo e apoiadores e investidores da UHE Belo Monte) e sendo assim gera grandes desigualdades.

6. Referências

BRASIL. Ministério de Minas e Energia. Projeto da Usina de Belo MontePerguntas Frequentes.

Disponível $\mathrm{em}:<$ http://www.epe.gov.br/leiloes/Documents/Leil\%C3\%A3o\%20Belo\%20Monte/Belo\%20 Monte\%20-\%20Perguntas\%20Frequentes\%20-\%20POR.pdf $>$ Acessado em: 10.10.2016.

BRASIL. Constituição Federal de 1988. Promulgada em 5 de outubro de 1988. Disponível em <http:/www.planalto.gov.br/ccivil_03/constituicao/constituição.htm Acesso: $20 / 09 / 2016$

CGEE - Centro de Gestão e Estudos Estratégicos. Estado da Arte e Tendências das Tecnologias para Energia. Janeiro de 2003. In Agenda elétrica sustentável 2020: estudos de cenário para um setor elétrico brasileiro eficiente, seguro e competitivo. $2^{\mathrm{a}}$ edição. Brasilia: Série técnica, 2007. 80 p.

ECOAMAZONIA. Justiça suspende Licença de Operação de Belo Monte por desobediência a decisão judicial. Disponível em: < http://www.ecoamazonia.org.br/2016/01/justica-suspende-licenca-operacao-belomonte-desobediencia-decisao-judicial/> Acessado em: 25.10.2016

FLEURY, L.C; ALMEIDA, J. A construção da Usina Hidrelétrica de Belo Monte: conflito ambiental e o dilema do desenvolvimento. São Paulo: Ambiente \& Sociedade, 2013. Disponível em: <http//www.scielo.br/pdf/asoc/v16n4/09.pdf> Acessado em: 21.10.2016 


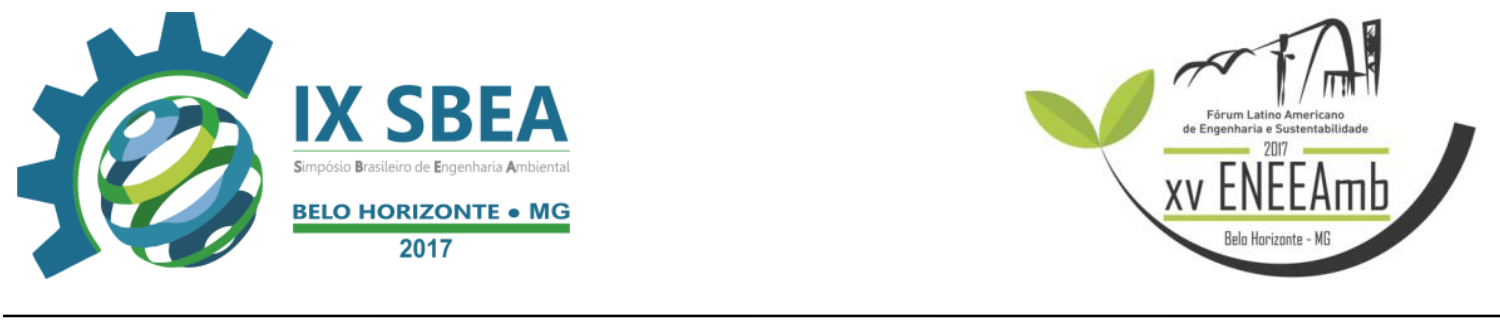

MARTINS, E.A. A constituição é um contrato leonino. Disponível : < http://www.saopauloindependente.org/blog/a-constituio-um-contrato-social-leonino> Acessado em: 25.10.2016

MTDX - Movimento Pelo Desenvolvimento da Transamazônica e Xingu. SOS XINGU- Um chamamento ao bom senso sobre o represamento de rios na Amazônia. Disponível em: http./www.riosvivos.org.br/. In: FLEURY, L.C; ALMEIDA, J. A construção da Usina Hidrelétrica de Belo Monte: conflito ambiental e o dilema do desenvolvimento. São Paulo: Ambiente \& Sociedade, 2013. Disponível em: <http://www.scielo.br/pdf/asoc/v16n4/09.pdf> Acessado em: 21.10.2016

MPF/PA. Tabela acompanhamento. Disponível em: $<$ http $/ /$ www.prpa.mpf.mp.br/news/2013/arquivos/Tabela_de_acompanhamento_atualiz ada_23-10-13.pdf> . Acessado: 25.09.2016

Nader, V. Mentira institucionalizada justifica Hidrelétrica de Belo Monte. Disponível em: <http://www.correiocidadania.com.br/content/view/1955/> Acessado: $\underline{25.09 .2016}$

NORTE ENERGIA. Usina Belo Monte. Disponível em: <http://www.blogbelomonte.com.br/usina-belo-monte/> Acessado em: 21.10.2016.

ROUSSEAU, Jean-Jacques. Do Contrato Social. Tradução de Ricardo Rodrigues da Gama. $1^{\text {a }}$ ed. São Paulo: Russel, 2006.

SROUR,S. A reforma do estado e a crise no setor de energia elétrica: uma visão crítica do caso brasileiro. Dissertação (Mestrado em administração) - Escola Brasileira

de Administração Pública e de Empresas, Fundação Getúlio Vargas, Rio de Janeiro. 2005.

WWF. Agenda elétrica sustentável 2020: estudos de cenário para um setor elétrico brasileiro eficiente, seguro e competitivo. $2^{\text {a }}$ edição. Brasilia: Série técnica, 2007. $80 \mathrm{p}$. 